\title{
"DE SAMBA-ENREDO DE CARNAVAL AO CONGRESSO NACIONAL": REFLEXÕES SOBRE A LEI DE ACESSO À INFORMAÇÃO FRENTE AO CONTROLE DA CORRUPÇÃO NO BRASIL
}

\author{
S.V.MACEDO ${ }^{1}$, J.L.VALADARES ${ }^{2}$ \\ Universidade Federal de Viçosa \\ ORCID ID: https://orcid.org/0000-0002-1610-1856 \\ susu.viana@hotmail.com ${ }^{1}$
}

DOI: $10.15628 /$ holos.2020.9786

\section{RESUMO}

Este ensaio teórico teve como objetivo analisar de que maneira a Lei de Acesso à Informação (LAI) pode contribuir para o controle da corrupção no Brasil. Com base na pesquisa bibliográfica desenvolvida por autores nacionais e internacionais e na análise de marcos regulatórios editados a partir da Constituição Federal de 1988 até a publicação da LAl em 2011, partiu-se do pressuposto que a transparência está além do estabelecimento de regras e de mecanismos burocráticos. A pesquisa, nesse contexto, abordou uma perspectiva que integra a publicidade não apenas como uma possibilidade de acessar os dados públicos e sim como uma prática que exige a participação ativa da sociedade civil tanto no recebimento das informações disponibilizadas pelo Estado quanto na utilização das mesmas em favor do interesse público. Além disso, abordou-se a necessidade de se implementar mecanismos efetivos de sanção para que o dever de informar se sobreponha às vontades dos agentes públicos. Avança-se, assim, nas discussões de que as reformas com foco no aumento da transparência devem ser acompanhadas de medidas que possam estimular o acesso e utilização das informações.

PALAVRAS-CHAVE: Administração pública, accountability, transparência, participação social, enforcement.

\section{"FROM SAMBA-SCHOOL THEME TO THE NATIONAL CONGRESS": REFLECTIONS ON THE ACCESS TO INFORMATION ACT IN FACE OF THE CONTROL OF CORRUPTION IN BRAZIL}

\begin{abstract}
This theoretical essay aimed to analyze how the Access to Information Law (AIL) can contribute to the control of corruption in Brazil. Through the analysis of regulatory frameworks edited from the Federal Constitution of 1988 until the publication of the LAI in 2011 and assuming that transparency is beyond the establishment of rules and bureaucratic mechanisms, the study considered a perspective that integrates advertising not merely as a possible way to access public data, but as a practice that requires active participation of the civil society, both
\end{abstract}

receiving and using the information provided by the State in favor of the public interest. In addition to that, the necessity of implementing effective mechanisms of sanction was discussed, so that the duty to inform precedes the willingness of public agents. Thus, there is progress in the discussions arguing that reforms aiming more transparency ought to be accompanied by measures that stimulate the access and use of the information.

KEYWORDS: Public administration, accountability, transparency, social engagement, enforcement. 


\section{INTRODUÇÃO}

A presença constante da corrupção e os seus consequentes efeitos sobre a gestão pública são assuntos que têm ganhado cada vez mais destaque no contexto político e social brasileiro. Existente no âmbito público e na seara privada, as suas implicações mais comuns elencadas pela literatura são a desigualdade social, a evasão de receita, a desaceleração do crescimento econômico, o direcionamento de recursos para atividades improdutivas, a instabilidade do regime político e das instituições que representam a base da democracia, bem como a desconfiança sobre as ações públicas (Iquiapaza \& Amaral, 2007; Avritzer \& Filgueiras, 2011; Power \& Taylor, 2011; Souza, Silva \& Gomes, 2017). Além dos seus resultados negativos, por ser um fenômeno que acompanha as sociedades desde a antiguidade, ocorrendo nos mais diversos países independentemente da condição econômica dos mesmos e do modelo de governo adotado (Martins, 2008; Filgueiras \& Aranha, 2011), o seu controle tornou-se um desafio para o governo brasileiro (Bueno, Brelàz \& Salinas, 2016).

Desde a colonização sabe-se que a corrupção já era uma prática corriqueira que, mesmo após a democratização do Estado, ainda permanece presente na administração pública brasileira. Como tal fenômeno é recorrente em sua história, além da criação e fortalecimento de órgãos burocráticos fiscalizadores, novos instrumentos legais também têm sido editados pelo governo federal brasileiro para tornar a gestão pública mais transparente e, via de consequência, prevenir e punir as práticas corruptas (Abrucio, Pedroti \& Pó, 2010; Macadar, Freitas \& Moreira, 2015). Em termos gerais, a transparência dos atos praticados pela gestão pública trata-se de uma exigência legal que está relacionada à ampliação da divulgação das informações públicas, por meio da implementação de mecanismos que facilitam o acesso.

Além disso, a literatura aponta que a promoção da transparência também deve permitir a construção de condições de accountability, no sentido de permitir aos cidadãos o acompanhamento, monitoramento e participação efetiva na administração pública (Peisakhin \& Pinto, 2010; Etzioni, 2010; Cruz et al., 2012; Michener \& Bersch, 2013). A implementação e regulamentação da transparência, nesse contexto, facilitou não só o acesso às informações coletadas, armazenadas e produzidas pelos entes, mas, também, criou novos obstáculos à prática da corrupção no setor público, visto que governos mais transparentes tendem a ser menos corruptos (Bastida \& Benito, 2007; Michener \& Bersch, 2011).

De modo geral, a partir da Constituição Federal de 1988 (Brasil, 1988) a transparência começou a receber um maior destaque na legislação brasileira (Raupp \& Pinho, 2013). Verificou-se um avanço mais efetivo com a publicação da Lei n. 12.527/11 (Brasil, 2011) que, além de estabelecer regras, prazos e procedimentos para a disponibilização e acesso às informações públicas, reforçou exigências legais de transparência dos atos praticados pela administração 
pública, já previstos no texto da Lei de Responsabilidade Fiscal (Brasil, 2000), incluindo suas posteriores alterações. Promulgada pelo governo federal em novembro de 2011, a Lei no. 12.527, conhecida como Lei de Acesso à Informação (LAI), reforçou o uso obrigatório de meios eletrônicos para a divulgação de um conjunto de informações consideradas essenciais à sociedade, comumente operacionalizadas na internet por meio de portais eletrônicos (Angélico, 2012).

Apesar da referida lei ter sido um avanço no que diz respeito ao acesso às informações públicas, deve-se ter em conta, também, que a transparência não se resume à mera divulgação dos atos públicos por meios oficiais (Filgueiras, 2011a). Conforme aponta Klitgaard (1988), a corrupção nasce em ambientes em que há incertezas, sendo menos prevalente quando há vasta disponibilidade de informação sobre o que o agente está ou não fazendo. Michener (2011), nesse sentido, pondera que a transparência tem o potencial dissipar a opacidade, considerada um reduto para a corrupção e ineficiência. Peisakhin e Pinto (2010), também argumentam que mecanismos anticorrupção são desenhados para superar o problema das assimetrias de poder e de informação.

A literatura, deste modo, aponta que os problemas ligados à corrupção no setor público podem estar relacionados à ausência de accountability e transparência, visto que governos menos corruptos tendem se ser mais transparentes (Bastida; Benito, 2007). Segundo Peisakhin e Pinto (2010), leis de acesso à informação pública estão entre as ferramentas mais eficazes para o combate à corrupção, visto que permitem à sociedade acompanhar o funcionamento da máquina pública. Nesse sentido, o estudo parte da premissa de que a transparência somente poderá contribuir de maneira efetiva para o controle da corrupção quando as informações disponibilizadas forem, de fato, alcançadas, recebidas e utilizadas pelo público, proporcionando condições verdadeiras de publicidade. Entretanto, considerando a constante presença da corrupção no setor público brasileiro, ainda paira a incerteza se a gestão pública já está estruturada para promover a transparência dos seus atos, tanto no sentido de disponibilizar suas informações, quanto de favorecer o controle e combate à corrupção.

Diante disso, levanta-se o seguinte questionamento: Qual o potencial de contribuição da Lei de Acesso à Informação no que se refere ao controle da corrupção no Brasil? O presente ensaio, deste modo, teve como objetivo geral analisar de que maneira a Lei de Acesso à Informação pode contribuir para o controle da corrupção no Brasil, bem como apresentar reflexões que ampliem a concepção da transparência para além do estabelecimento de regras e de mecanismos burocráticos. Assim, buscou-se abordar uma perspectiva que integre a publicidade não apenas como uma possibilidade de acessar dados públicos, e sim como uma prática que exige a participação ativa da sociedade civil e que, acaso descumprida pela administração pública, seja passível de sanção tanto pelos cidadãos quanto pelo Estado. Esse debate faz se importante em virtude da relevância que a questão da corrupção aliada à transparência tem ganhado no contexto brasileiro.

A pesquisa, nesse sentido, avança nas discussões de que as reformas com foco no aumento da transparência no Brasil merecem ser acompanhadas de medidas para estimular o acesso e 
utilização das informações disponíveis e fortalecer a capacidade dos gestores de agir com idoneidade. A transparência não é uma solução rápida, por isso, para que ela possa contribuir de forma efetiva no controle da corrupção, ela depende de outros fatores que podem levar um tempo para serem aceitos e se consolidarem.

Com base na pesquisa bibliográfica desenvolvida por autores nacionais e internacionais e por meio da análise de marcos regulatórios editados a partir da Constituição Federal de 1988 até a publicação da LAl em 2011, este trabalho, estruturado no formato de ensaio teórico, está organizado em cinco seções, a começar por esta introdução. A segunda é dedicada a apresentar as formas de controle da corrupção no Brasil. Na terceira seção expõe-se como a transparência e o direito ao acesso à informação são tratados pela administração pública brasileira. Na quarta seção são apontadas e discutidas as potencialidades da Lei de Acesso à Informação, os seus desafios, bem como a necessidade de se ampliar a compreensão da transparência. Na quinta seção, enfim, são apresentadas as considerações finais.

\section{O CONTROLE DA CORRUPÇÃO NO BRASIL}

A avalanche de escândalos divulgados pela mídia sobre a corrupção na administração pública brasileira tem produzido a ideia de que tal fenômeno têm se tornado mais recorrente. Sabe-se, contudo, que tal prática não é um assunto novo e que a ampliação dos meios de comunicação, propiciada principalmente pela internet, tem facilitado que os atos corruptos praticados cheguem ao conhecimento dos cidadãos mais rapidamente. Enquanto na maioria dos crimes há sempre uma vítima ou indivíduo envolvido que se propõe a denunciar, nos casos da corrupção os agentes envolvidos buscam a todo custo minimizar a possibilidade de descoberta de seus atos, o que dificulta a apuração desse fenômeno e a sua consequente punição (Gingerich, 2006).

Deste modo, em virtude das barreiras que normalmente existem para se detectar a prática de atividades corruptas, o seu controle tornou-se uma difícil tarefa para a administração pública brasileira, pois depende de uma logística que abrange diferentes sistemas de accountability (Peruzzotti, 2008; Bueno, Brelàz \& Salinas, 2016). O termo accountability, em geral, está presente nos estudos da administração pública quando se aborda questões relacionadas à participação, prestação de contas, transparência, controle e responsabilização dos agentes (Abrucio \& Loureiro, 2004; Koppell, 2005; Medeiros, Crantschaninov \& Silva, 2013). Quanto ao seu conceito, Pinho e Sacramento (2009, p. 1348) apresentam a definição do termo como "a responsabilidade, a obrigação e a responsabilização de quem ocupa um cargo em prestar contas segundo os parâmetros da lei, estando envolvida a possibilidade de ônus, o que seria a pena para o não cumprimento dessa diretiva".

No mesmo sentido, conforme Przeworski (1998) quando os cidadãos têm a possibilidade de saber se seus representantes estão atuando ou não em favor dos interesses públicos, podendo 
ainda aplicar sanções aos que violarem os deveres públicos, é possível falar em um governo accountable. A prestação de contas e a possibilidade de impor penalidades, portanto, são elementos essenciais à efetivação da accountability. A propósito, na concepção de Schedler (1999) o processo da accountability deve integrar três dimensões que previnem e combatem o abuso de poder político, sendo estas, a da informação, da justificação e da sanção. As duas primeiras constituem o que o autor chama de answerability, que se refere à obrigação dos atores públicos prestarem contas, informando e explicando os motivos das suas escolhas e seus atos. Já a terceira dimensão diz respeito à capacidade das agências de controle e do cidadão em aplicar sanções aos atores públicos que violaram determinadas regras de conduta, denominada pelo autor de enforcement.

Assim, analisando tais pressupostos, considera-se que a accountability envolve o direito dos cidadãos de serem informados sobre as decisões e ações executadas pelo poder público, bem como a necessidade dos agentes de explicar suas decisões, devendo atuar dentro dos limites da lei, sob pena da imposição de sanção se acaso assim não proceder. Avançando nas discussões, O'Donnell (1998) destaca que a accountability divide-se em duas categorias, uma horizontal e outra vertical. A primeira se perfaz por meio de uma mútua fiscalização entre os poderes do Estado ou seus respectivos órgãos públicos, configurando o chamando mecanismo de checks and balances. Tratase, deste modo, da capacidade e dever que determinadas agências estatais ou órgãos públicos têm de realizar ações que implicam na supervisão de atos e até mesmo aplicação de sanções no caso de práticas delituosas, pressupondo uma relação entre iguais (O'donnell, 1998; Barreda, 2014).

A dimensão vertical, por outro lado, abrange a relação entre Estado e sociedade, pressupondo uma ação entre atores desiguais. Sua realização ocorre por meio de eleições justas e limpas, nas quais o cidadão confere livremente o seu voto a quem julgar merecedor (O'donnell, 1998; Pinho \& Sacramento, 2009). Ampliando esse último conceito, a accountability societal, segundo Peruzzoti e Smulovitz (2006), é um mecanismo de controle vertical, não eleitoral, do poder público, de caráter não estatal (Filgueiras, 2011b), estendendo-se às organizações da sociedade civil. Considera-se, dessa forma, que a accountability, em seu sentido amplo, está relacionada à ideia de controle dos atos praticados pelos agentes públicos, podendo ser exercida por meio de um conjunto de elementos, dentro os quais a transparência dos dados e decisões públicas, o acesso à informação, a participação social e os mecanismos burocráticos do Estado assumem um papel de destaque, principalmente, quando o assunto é a corrupção no setor público.

Partindo de tais conceitos, Avritzer e Filgueiras (2011, p. 16) apontam que o controle democrático da corrupção "deve estar balizado em uma concepção tridimensional e integrada, de acordo com um ideal político de interesse público", por meio da associação entre os controles administrativo-burocrático, judicial e público não-estatal. Fundamentado em uma concepção de accountability horizontal, o controle administrativo-burocrático é aquele realizado por agências do governo especializadas em fiscalizar as práticas realizadas pelos agentes públicos no exercício de suas funções, podendo ser executado tanto internamente quanto externamente (Avritzer \& 
Filgueiras, 2011). Dentre os inúmeros órgãos governamentais que contribuem para o controle e combate dos níveis de corrupção no país, pode-se destacar, em nível federal, a Controladoria Geral da União (CGU), que passou a integrar, desde maio de 2016, o Ministério da Fiscalização, Transparência e Controle; a Advocacia-Geral da União (AGU); o Ministério Público Federal ou Estadual; o Tribunal de Contas da União (TCU); a Polícia Federal (PF) e o Conselho de Controle de Atividades Financeiras (COAF) (Loureiro, Teixeira \&Moraes, 2009; Olivieri, 2011).

O controle judicial, por sua vez, é exercido pelo poder judiciário, tendo em conta um sistema de leis e regulamentos interpretados à luz de uma jurisprudência constituída pela magistratura, no âmbito da seara cível e penal (Barboza Filho, 2008; Filgueiras, 2008). Essa vigilância jurídica retira do campo da burocracia o controle de fiscalizar os seus próprios atos e transfere para o judiciário a função de controlar as ações dos agentes públicos, utilizando a lei para interpretar se determinada prática é corrupta ou não, bem como para responsabilizar civilmente e atribuir penas aos crimes cometidos contra a gestão pública (Avritzer \& Filgueiras, 2011). Vale destacar, que em virtude da capacidade que o judiciário tem de revisar as decisões administrativas existe uma sobreposição do controle judicial sobre o controle administrativo-burocrático (Avritzer \& Filgueiras, 2011).

Diferentemente do controle judicial e do controle administrativo-burocrático que são efetuados por poderes do Estado ou por seus órgãos, o controle público não estatal deixa de estar vinculado às instituições do governo, sendo exercido pela sociedade civil, movimentos públicos ou associações civis (Peruzzotti, 2008). Trata-se, dessa forma, de um meio de controle que está fundamentado no interesse público não como algo derivado da lei, mas como fruto de processos deliberativos e discursivos realizados pelos cidadãos (Avritzer \& Filgueiras, 2011). Baseado na noção de accountability vertical, esse tipo de controle está ligado à promoção do debate público pelos cidadãos fora das estruturas do poder, em que os processos participativos são fatores determinantes para a construção da ideia de interesse público, possibilitando aos cidadãos controlar as ações governamentais e auxiliar a determinar as decisões por meio de uma dimensão participativa (Filgueiras, 2008).

Sintetizando essas ideias, o Quadro 01, a seguir, detalha cada uma das formas de controle apontadas neste estudo.

Quadro 1: Modalidades de controle da corrupção no Brasil

\begin{tabular}{|c|c|c|c|}
\hline Dimensão & Estado & & Sociedade \\
\hline Tipos de controle & $\begin{array}{c}\text { Controle } \\
\text { administrativo-burocrático }\end{array}$ & Controle judicial & $\begin{array}{c}\text { Controle público } \\
\text { não estatal }\end{array}$ \\
\hline Agentes & $\begin{array}{c}\text { Agências especializadas } \\
\text { (controle interno e externo) }\end{array}$ & Tribunais & $\begin{array}{l}\text { Sociedade civil e } \\
\text { representação funcional }\end{array}$ \\
\hline $\begin{array}{c}\text { Fundamento } \\
\text { Normativo }\end{array}$ & Legalidade & Legalidade & Participação \\
\hline Prática & Sanções administrativas & $\begin{array}{l}\text { Interpretação da } \\
\text { Lei }\end{array}$ & $\begin{array}{c}\text { Exercício da liberdade } \\
\text { política }\end{array}$ \\
\hline
\end{tabular}




\begin{tabular}{|c|c|c|c|}
\hline Consequências & Regulação & Criminalização & Publicidade \\
\hline
\end{tabular}

Fonte: Avritzer e Filgueiras (2011, p. 21).

O Brasil, desta maneira, dispõe de um amplo sistema que visa promover um serviço público mais íntegro, buscando o enfrentamento da corrupção, principalmente, por meio do fortalecimento da accountability horizontal. Destaca-se, contudo, que nenhuma dessas instituições responsáveis pela fiscalização das rotinas e punição dos infratores tem a função exclusiva de controlar a corrupção, nem concentram todas as fases do processo de accountability, que envolve desde o monitoramento até a aplicação de penalidades (Olivieri, 2011; Aranha, 2015). Além disso, segundo Avritzer e Filgueiras (2011), devido ao fato dos mecanismos de accountability horizontal se sobressaírem aos demais, há uma disjunção entre as dimensões do controle da corrupção.

Desde a Constituição Federal de 1988 o controle administrativo-burocrático tem crescido, principalmente, no âmbito federal. Todavia, ao mesmo passo em que o controle sobre a burocracia aumentou, os recorrentes escândalos relacionados à corrupção no setor público brasileiro aliados à baixa punição judicial contra aqueles que praticam atos corruptos têm contribuído para fortalecer o pressuposto de que os mecanismos de accountability existentes no Brasil ainda são frágeis (Campos, 1990; Power \& Taylor, 2011, Aranha, 2015).

Tal fato, por conseguinte, provoca na opinião pública a percepção de que o simples cumprimento das leis ou enrijecimento delas e de mecanismos burocráticos de vigilância podem obstar a impunidade, diminuindo, via de consequência, a corrupção (Avritzer \& Filgueiras, 2011). Criou-se, dessa forma, no imaginário social, a ideia de que tais fatores, por si só, resolveriam o problema da corrupção no Brasil. Essa ampliação do controle administrativo-burocrático e do controle judicial, todavia, resultaram no enfraquecimento do controle público não estatal da corrupção, sem o qual não será possível avançar no combate das práticas corruptas (Avritzer \& Filgueiras, 2011).

O controle democrático da corrupção no Brasil, além da integração entre os controles administrativo-burocrático, judicial e público não estatal, requer uma maior atenção à dimensão da participação da sociedade nos processos de escolhas e decisões públicas. Embora a implementação de mecanismos burocráticos de controle e de penalidades seja necessário, isso não significa que o comportamento dos indivíduos seguirá as mudanças criadas rapidamente (Campos, 1990; O'donnell, 1991; Aranha, 2015). Para que o processo de accountability seja efetivo, mostra-se igualmente necessário o engajamento da sociedade civil nessa luta. Nesse contexto, a transparência dos atos praticados administração pública e, especificamente, o acesso às informações produzidas pelos respectivos entes, podem ser aliados na promoção da cidadania, pois têm a capacidade de impulsionar o controle da sociedade sobre a atuação dos agentes públicos, auxiliando no combate à corrupção. 


\section{A TRANSPARÊNCIA E O DIREITO AO ACESSO À INFORMAÇÃO}

O modelo gerencial da Nova Administração Pública, considerando o pressuposto de que a burocracia deve ser controlada a fim evitar práticas ilegais pelos agentes públicos (Graaf, 2007), trouxe um conjunto de políticas reformistas voltadas para a promoção da transparência, no sentido de fortalecer um sistema de integridade com o aprimoramento de mecanismos de controle da gestão e da responsabilização fiscal (Jardim, 1999; Vigoda-Gadot \& Meiri, 2008; Abrucio, Pedroti \& Pó, 2010). Em termos conceituais, a transparência pode ser compreendida como a gestão dos assuntos públicos destinados ao público, sendo o oposto de políticas opacas, nas quais não se tem acesso às decisões que são tomadas e ao que elas representam (Michener \& Bersch, 2011; Suzart, 2012). A promoção da transparência, deste modo, está relacionada ao desenvolvimento, implementação e disponibilização de instrumentos que facilitam o conhecimento e o acompanhamento das políticas e ações praticadas no âmbito público pelos cidadãos (Albuquerque, Medeiros \& Feijó, 2006).

Assim, para colocar em prática uma política de transparência necessita-se de uma disposição da administração pública em se abrir, aumentando a permeabilidade do Estado, bem como de levar a público informações que garantam que as demandas da sociedade possam efetivamente influenciar a atividade governamental (Filho, 2005). Sob essa perspectiva, considera-se que a "transparência e abertura de governo são, sem dúvida, pilares essenciais à construção de qualquer sociedade democrática. Não há, entretanto, possibilidade real de se firmarem sem que seja garantido ao cidadão o acesso à informação pública e o amplo conhecimento de tudo o que o Estado faz no exercício de sua função" (Mendanha, 2009, 69).

Embora a transparência não se restrinja apenas às obrigações dispostas em lei, a discussão sobre o acesso à informação no Brasil envolve a perspectiva normativa ao qual ele está relacionado. De modo geral, esse assunto começou a receber maior atenção pela legislação após a Constituição Federal (Brasil, 1988), que positivou a publicidade como princípio constitucional e estabeleceu o acesso às informações públicas como um direito (Bernardes, Santos \& Rover, 2015). Apesar disso, a permanência da cultura do sigilo fez aumentar a necessidade de se estabelecer regras sobre a disponibilização de informações públicas (Angélico \& Teixeira, 2012). Tal fato, por conseguinte, estimulou a promulgação da Lei Complementar no. 101, de 04 de maio de 2000, denominada Lei de Responsabilidade Fiscal (Brasil, 2000), cuja finalidade era institucionalizar a responsabilidade na gestão fiscal e instigar ação planejada.

Posteriormente, a referida lei teve, por meio da Lei Complementar no 131/09 (Brasil, 2009), acréscimos quanto à divulgação de seus dados, sendo estabelecida a disponibilização, em tempo real, de informações detalhadas sobre a execução orçamentária e financeira da União, dos Estados, do Distrito Federal e dos Municípios, criando os conhecidos portais da transparência. Tais informações, contudo, por possuírem apenas caráter orçamentário e financeiro, não ofereciam 
outros tipos de dados que permitissem o acompanhamento dos programas realizados pelo governo. Ademais, não havia nenhuma disposição relacionada aos prazos e procedimentos que a administração pública deveria adotar nos casos em que o cidadão necessitava obter algum tipo de informação. Diante disso, inspirado na tendência mundial de efetivo acesso à informação e concretizando as declarações e pactos aos quais se submeteu (Mendel, 2009), em novembro de 2011 o governo federal brasileiro promulgou a Lei no. 12.527, denominada Lei de Acesso à Informação (LAI).

Apesar de confirmar algumas determinações legais já previstas em leis anteriores, a LAI avançou no que se refere à disponibilização de informações que não se restringem a dados puramente fiscais. A propósito, antes, contudo, da promulgação da Lei de Acesso à Informação já havia algumas previsões, dispersas em leis distintas, que tratavam de forma indireta e secundária a questão do acesso às informações em ambientes públicos. O Quadro 02, nesse sentido, enumera os instrumentos normativos de âmbito nacional que, aos poucos, foram introduzindo pequenos preceitos sobre o acesso à informação no Brasil, até a sua regulamentação efetiva pela Lei no. 12.527/2011. Destaca-se que, além das leis apresentadas, outras normas nacionais também trouxeram algumas disposições mínimas sobre esse assunto, optou-se, no entanto, por apresentar aquelas que inseriram alterações mais relevantes no contexto legal.

Quadro 02: Marcos legais do acesso à informação no Brasil

\begin{tabular}{|c|c|}
\hline Marcos Legais & Descrição \\
\hline $\begin{array}{l}\text { Constituição Federal } \\
\text { de } 1988\end{array}$ & Estabelece o acesso à informação como direito dos cidadãos \\
\hline Lei no 8.159/91 & $\begin{array}{l}\text { Dispõe sobre a política nacional de arquivos públicos e privados, } \\
\text { estabelecendo o dever do Poder Público manter a gestão documental como } \\
\text { elemento de prova e informação }\end{array}$ \\
\hline Lei no. 8.429/92 & $\begin{array}{l}\text { Prevê que a negativa de publicidade configura o crime de improbidade } \\
\text { administrativa }\end{array}$ \\
\hline Lei no 9.507/97 & $\begin{array}{l}\text { Regulamenta o Habeas Data e assegura o direito de acesso à informação em } \\
\text { banco de dados }\end{array}$ \\
\hline $\begin{array}{l}\text { Emenda Constitucional no. } \\
\qquad 19 / 98\end{array}$ & $\begin{array}{l}\text { Altera o art. } 37 \text { da CF/88 para assegurar a eficiência na administração e o } \\
\text { direito de os administrados obterem informações dos dados } \\
\text { governamentais }\end{array}$ \\
\hline Lei no. 9.755/98 & Criação do sítio pelo TCU para divulgar contas públicas \\
\hline Lei no 9.784/99 & $\begin{array}{l}\text { Lei do Processo Administrativo, dispõe sobre a obrigatoriedade de } \\
\text { publicação oficial dos atos administrativos }\end{array}$ \\
\hline $\begin{array}{l}\text { Lei Complementar no } \\
\qquad 101 / 00\end{array}$ & $\begin{array}{l}\text { Estabelece normas de finanças públicas voltadas para a responsabilidade na } \\
\text { gestão fiscal }\end{array}$ \\
\hline Lei no. 11.111/05 & $\begin{array}{l}\text { Regulamenta a parte final do disposto no inciso XXXIII do caput do art. 50 da } \\
\text { Constituição Federal, dispondo sobre o sigilo de informações e documentos } \\
\text { públicos }\end{array}$ \\
\hline $\begin{array}{l}\text { Lei Complementar no } \\
\qquad 131 / 09\end{array}$ & $\begin{array}{l}\text { Alterou a LRF e previu a obrigatoriedade da prestação de contas públicas na } \\
\text { internet }\end{array}$ \\
\hline Lei $n$ o $12.527 / 11$ & Lei de Acesso à Informação \\
\hline
\end{tabular}

Fonte: Elaboração própria com base nos estudos de Bernardes, Santos e Rover (2014). 
Ao regulamentar o inciso XXXIII do art. 5으, o inciso II do § 3ㅇ do art. 37 e o § 2ㅇ do art. 216 da Constituição Federal (Brasil, 1988), o Brasil tornou-se o 89 país a implementar uma lei de acesso à informação, que entrou em vigor em 16 de maio de 2012 (Angélico, 2012). A Lei de Acesso à Informação brasileira, em termos gerais, estabeleceu as bases para que a transparência se realizasse de forma ativa e passiva. No que se refere à transparência ativa, o art. 8 o da referida norma prevê um rol mínimo, não taxativo, de informações que os órgãos e entidades públicas devem, obrigatoriamente, divulgar na internet. Detalha, ainda, quais os elementos que devem estar nos sites, tais como ferramentas de pesquisa, publicação de dados em formato aberto e mecanismos de acessibilidade para pessoas com deficiência. Já a transparência passiva, consoante previsto no art. 10 da LAl, ocorre mediante apresentação de requerimento perante o órgão ou ente público para obtenção de informações que não estão dispostas nos portais eletrônicos e que não sejam resguardadas por sigilo, devendo o pedido conter a identificação do requerente e a especificação da informação requerida. Tais requerimentos dispensam motivação e devem ser gratuitos.

Além da obrigatoriedade da implantação de um serviço de informação ao cidadão na modalidade física, a Lei de Acesso à Informação também determina que os órgãos e entidades públicas, não importando o porte do município, devem viabilizar alternativa de encaminhamento de pedidos de acesso por meio da internet (Controladoria-Geral da União, 2013). Segundo o artigo 11 da LAI, não sendo possível conceder o acesso imediato, o órgão ou entidade que receber o pedido terá o prazo de vinte dias para respondê-lo, prorrogável por mais dez, mediante justificativa expressa, da qual será cientificado o requerente. A propósito, o art. 45 da referida norma define que cabe aos Estados, ao Distrito Federal e aos Municípios definir suas regras específicas em legislação própria, obedecidas as normas gerais estabelecidas na lei. Contudo, ressalta-se que os dispositivos gerais têm aplicação imediata, portanto, a falta de regulamentação específica não impede o seu cumprimento.

Nos termos do artigo 20 da LAl, os procedimentos por ela previstos aplicam-se à União, Estados, Distrito Federal e Municípios, contemplando, também, quaisquer dos órgãos públicos integrantes da administração direta dos Poderes Executivo, Legislativo, incluindo as Cortes de Contas, e do Judiciário e do Ministério Público, além das autarquias, as fundações públicas, as empresas públicas, as sociedades de economia mista e demais entidades controladas direta ou indiretamente pelas três esferas de poder. Destaca-se, que os municípios com menos de dez mil habitantes, conforme previsto no art. 8ㅇ, §4으 da LAI, ficam dispensados da divulgação obrigatória na internet do chamado rol mínimo de informações, ficando para esses a obrigatoriedade de cumprimento apenas das informações financeiras e orçamentárias, nos critérios e prazos previstos na Lei de Responsabilidade Fiscal.

Aliado à promulgação das legislações relativas ao acesso à informação pública, um fator que contribuiu para o aperfeiçoamento dos processos de transparência pública foi o desenvolvimento e ampla utilização das Tecnologias da Informação e da Comunicação (TICs) nos setores 
governamentais (Curtin \& Meijer, 2006; Licht, 2014). Em geral, as TICs têm se espalhado pela administração pública por meio do e-gov ou governo eletrônico, representado pela construção de portais governamentais na internet, mediante os quais as entidades expõem uma série informações. A LAI, nesse sentido, não só ampliou o rol de informações que devem ser disponibilizadas, mas, também, consolidou e tornou obrigatória a utilização de meios eletrônicos como forma de facilitar o acesso.

A Lei de Acesso à Informação também estabelece que a divulgação obrigatória em sítios oficiais da rede mundial de computadores deve ser objetiva, clara e em linguagem de fácil acesso. Os portais ainda devem atender aos requisitos de garantia de autenticidade e integridade das informações disponíveis, mantê-las atualizadas, indicar o local e fornecer instruções que permitam ao interessado comunicar-se, por via eletrônica ou telefônica, com o órgão ou entidade detentora do site, além de adotar medidas necessárias para garantir a acessibilidade de conteúdo. Assim, a simples informação por si só não é o suficiente para que a transparência seja efetiva, é necessário, de igual modo, que a disponibilização dos dados públicos por meio eletrônico seja de fácil acesso pelos cidadãos e que as informações sejam compreensíveis e coesas (Cruz et al., 2012).

Deste modo, apesar da sua importância para a gestão pública, os instrumentos que ajudam a promover a transparência, como ocorre com a Lei de Acesso à Informação, não é um fim em si mesmo. Assim, não serão o bastante para controlar o problema da corrupção se não estiverem acompanhados de mecanismos que contribuam para que a informação disponibilizada seja recebida, compreendida e utilizada pelos cidadãos e que, além disso, reforcem a capacidade de impor sanções a aqueles que vão de encontro aos interesses públicos. A criação de instrumentos legais, como é o caso da LAl, é apenas uma etapa na estruturação de uma política efetiva de transparência no país.

\section{A LEI DE ACESSO À INFORMAÇÃO FRENTE AO CONTROLE DA CORRUPÇÃO}

Ao regulamentar um direito que já estava previsto na Constituição Federal do Brasil de 1988, a Lei no. 12.527/11 possibilitou a abertura dos atos administrativos praticados pelo governo brasileiro, no sentido de torná-los mais transparentes aos cidadãos e, consequentemente, mais afeitos à observação da sociedade. Os mecanismos de transparência instituídos pela Lei de Acesso à Informação, considerando a opacidade informacional existente no país, significaram um avanço no marco regulatório do país no que se refere à ampliação da disponibilização dos dados públicos, bem como do uso das TICs para a obtenção de informações. Embora a referida norma não tenha sido criada com a finalidade de controlar as práticas corruptas, até mesmo porque não possui qualquer dispositivo específico relacionado a esse assunto, o fato de propiciar a obtenção de informações públicas que antes permaneciam em sigilo, bem como favorecer o processo de fiscalização e monitoramento da gestão pública, contribuem para o fortalecimento do controle da corrupção. 
No que se refere ao controle administrativo-burocrático, a Lei de Acesso à Informação facilitou o serviço das agências do governo especializadas em acompanhar as atividades realizadas pela administração pública, de modo que, as informações disponibilizadas pelos entes são substratos para essas agências fiscalizarem, apurarem e determinarem a correção das eventuais práticas ilegais cometidas pelos agentes públicos e políticos no exercício de suas funções. Aliás, a Controladoria Geral da União (CGU) juntamente com o Ministério Público Federal (MPF) ocupam papéis centrais no monitoramento e orientação dos órgãos e entidades do Poder Executivo Federal com relação ao cumprimento dos dispositivos da Lei de Acesso à Informação. Destaca-se, entretanto, que a criação desenfreada dos órgãos de controle pode prejudicar a eficiência do Estado, por isso, na visão de Anechiarico e Jacobs (1996) e Avritzer e Filgueiras (2011) o controle administrativo-burocrático deve manter o equilíbrio entre a busca pela integridade no serviço público e a eficiência da administração pública.

Quanto ao controle judicial da corrupção, apesar da sua relação com a LAI não ser direta, o descumprimento injustificado de pedidos de acesso a informações públicas, nos termos do seu art. 32 , é ato ilegal, sujeitando seus infratores a sanções administrativas e até mesmo à condenação civil e penal por ato de improbidade administrativa. De igual modo, a regulamentação da obrigação de todos os órgãos e entidades públicas divulgarem seus dados públicos de forma espontânea nos sítios eletrônicos; a possiblidade dos cidadãos requererem, diretamente no respectivo órgão ou por meio eletrônico, informações que são do seu interesse sem apresentar qualquer justificativa e o dever dos entes governamentais instalarem o Serviço de Informação ao Consumidor (SIC) eletrônico e presencial, representam elementos fundamentais para o exercício da democracia no Brasil, propiciando um maior controle da sociedade sobre gastos e políticas públicas, contribuindo para o controle público não estatal da corrupção (Michener, Moncau \& Velasco, 2014).

Deste modo, pode-se dizer que a adoção de instrumentos de transparência por meio de uma lei que visa garantir o acesso à informação pode proporcionar o alcance de benefícios como um maior controle da corrupção, bem como a melhoria da relação entre Estado e Sociedade por meio do reforço da participação social (Angélico \& Teixeira, 2012). Por outro lado, ainda há alguns aspectos da Lei de Acesso à Informação que precisam ser melhor estruturados. Apesar de sua aplicação se estender à todos os órgãos públicos integrantes da administração direta e indireta, incluindo os três poderes em todo os seus três níveis de governo, os municípios com menos de dez mil habitantes, conforme previsto em seu art. 8oㅗㄴำ, estão dispensados da divulgação obrigatória na internet do chamado rol mínimo de informações, ficando apenas a obrigatoriedade de cumprimento dos critérios e prazos previstos na Lei de Responsabilidade Fiscal.

Embora isso não signifique que tais municípios estejam dispensados de seguir as diretrizes da LAI, o fato da lei não os obrigar a disponibilizarem eletronicamente suas informações acaba reduzindo as chances destes entes adotarem as práticas instituídas pela referida norma. A lei não é o suficiente para que a transparência pública seja efetiva, mas considerando o poder de 
enforcement que ela exerce sobre os governantes e que muito daquilo que a administração pública brasileira hoje executa depende da existência de uma lei que converte determinadas ações em obrigações, a sua completa ausência pode trazer maiores obstáculos à consolidação do acesso à informação. Estudos como o de Michener (2016), por exemplo, apontam que o aumento expressivo das iniciativas relacionadas à ampliação dos mecanismos de transparência vem ocorrendo principalmente no nível federal, sendo que o processo de implementação das determinações previstas na LAI ainda encontra entraves no âmbito municipal.

Um outro fator que também pode restringir o direito ao acesso à informação refere-se à necessidade do cidadão solicitante ter que se identificar ao realizar o pedido. Tal prática pode violar o princípio da isonomia do serviço público. Segundo a pesquisa de Michener (2016) há um grande risco de intimidação, principalmente, em municípios menores, nos quais os servidores podem identificar sem qualquer embaraço quem solicitou a informação. Como as informações obtidas podem ensejar denúncias e a identificação do solicitante, por questões de rivalidades, pode atrasar o fornecimento dos dados requeridos, o anonimato de quem requer a informação é mais recomendável que a sua identificação. Outro obstáculo à consolidação da Lei de Acesso à Informação está relacionado à forma como as informações são disponibilizadas pelos portais governamentais brasileiros.

Embora a garantia legal do amplo acesso à informação exija que a administração pública proporcione informações amplas, claras, fáceis de serem entendidas e absorvidas pelo cidadão e que não demande conhecimentos específicos na seara contábil, orçamentária ou jurídica, os estudos revelam que os dados disponibilizados ainda são de difícil compreensão (Zuccolotto \& Teixeira, 2015; Araujo \& Tejedo-Romero, 2016; Figueiredo \& Gazoni, 2016). Em virtude disso, muitas vezes os portais eletrônicos estão presentes, mas a existência dos mesmos parece simplesmente atender às exigências tecnológicas, funcionando como murais eletrônicos ao invés de institucionalizarem a cultura de acesso (Raupp, 2014).

Além dessas questões, obstáculos socioculturais como a pouca divulgação a respeito do direito à informação e de apoio à norma, o baixo nível de sanções aplicadas para os casos de descumprimento da lei, a falta do uso prático das previsões que a norma oferece por medo de perseguição por parte dos governantes, bem como a baixa atuação da sociedade em demandar informação e requerer reformas institucionais que possam fortalecer e estimular o acesso à informação, também podem dificultar o fortalecimento da norma em questão e, via de consequência, a construção de condições verdadeiras de transparência na gestão pública (Angélico, 2012; Michener \& Bersch, 2013).

Apesar da transparência não se restringir a simples elaboração de instrumentos normativos, o poder de coerção (enforcement) do qual a lei é revestida, em um país no qual as ações do governo são fortemente baseadas por imposições legais, é um impulso para a promoção do acesso à informação. Todavia, mais do que simplesmente cumprir a lei, deve-se atender às reais 
necessidades dos usuários, transformando as informações públicas disponibilizadas em uma ferramenta que seja efetiva para os cidadãos. Por tal razão, a disponibilização dos dados públicos é apenas um passo para construção de uma política de transparência no país, é necessário, ainda, evoluir no desenvolvimento de oportunidades que propiciem um maior envolvimento e participação da sociedade na condução das decisões e das atividades de gestão dos governos, fazendo com que as informações disponibilizadas também sejam recebidas, entendidas e utilizadas pela sociedade.

Como se trata de uma lei que conta com aproximadamente seis anos de vigência, a tarefa de transformar a cultura do sigilo não é tão simples quanto parece. O principal foco da administração pública brasileira tanto no que se refere à corrupção quanto à política de transparência é a ampliação dos mecanismos de controle administrativos-burocráticos e judiciais. É o Estado por meio das agências especializadas em fiscalizar os poderes públicos e a lei através das normas que preveem o que pode ou não ser feito que detêm o poder de controlar a corrupção e de propiciar uma maior transparência.

Nesse cenário, enquanto o Estado possui o papel de ator principal na regulação da vida social, a sociedade permanece como uma simples coadjuvante, que apenas cumpre e absorve o que Ihe é concedido pelo governo, sem correr atrás do que julga ser o melhor para a gestão pública (Carvalho, 2007; Andrade, Castro \&Pereira, 2012). O livre acesso à informação, inclusive, é um exemplo disso, visto que a sua previsão na Constituição Federal (Brasil, 1988) não foi o suficiente para que os cidadãos lutassem e conquistassem de maneira efetiva tal direito, sendo necessário, ainda, que a Lei no. 12.527/2011 o regulamentasse posteriormente.

Observa-se que ainda falta à sociedade brasileira, de modo geral, a percepção de que os seus direitos são muito mais do que uma previsão da lei e que vão muito além disso. O ordenamento jurídico, neste caso, é apenas a materialização de algo que foi construído. Essa estruturação, entretanto, não depende apenas do Estado, ela não só pode como deve partir também do próprio cidadão. Os seus direitos, dessa forma, devem ser efetivamente exercidos e isso depende de sujeitos sociais ativos que reconheçam e pratiquem, antes de tudo, o direito de participarem dos processos e decisões públicas (Dagnino, 2004). Pensar a transparência na administração pública brasileira de uma forma mais ampla e que não compreenda apenas o livre acesso à informação como condição suficiente para o controle dos atos administrativos, remete à ideia de participação dos cidadãos e diálogo entre o Estado e a sociedade.

Para além de tão somente disponibilizar informações, mostra-se igualmente necessário que haja o uso dos mecanismos previstos na referida norma pela sociedade civil e, também, que os governantes assumam compromissos políticos e administrativos no que se refere a implementação de políticas públicas que promovam o direito à informação e que realizem a inclusão digital e o suporte à Lei de Acesso à Informação. Do mesmo modo, tratar o controle da corrupção de maneira mais integrada significa trazer para o debate a relevância de se promover a efetiva participação dos 
cidadãos nos processos discursivos de elaboração da opinião e da vontade pública. Apenas assistir inerte aos escândalos relacionados à corrupção que corrói a administração pública brasileira, deixando a cargo do Estado o poder de controlar a prática de tais atos não tem sido o bastante para impedir a presença constante da corrupção e dos seus malefícios contra à gestão pública.

Diante disso, entende-se que a Lei de Acesso à Informação, como mecanismo de transparência, publicidade e enforcement, contribui para o controle da corrupção no Brasil, principalmente por ter o potencial de proporcionar uma interação mais dinâmica entre o Estado e a sociedade. Destaca-se, entretanto, que os mecanismos burocráticos e judiciais, embora sejam essenciais e tenham a sua importância, não são o suficiente para um controle mais efetivo da corrupção. É necessário, também, que a participação do cidadão na formação da vontade pública avance junto com essas medidas, por meio da consolidação de uma política na qual os múltiplos públicos possam ter voz ativa, dando efetividade à dimensão do controle público não estatal. Assim, as reformas com foco no aumento da transparência e no controle da corrupção também devem ser acompanhadas de medidas que estimulem o acesso e utilização das informações disponíveis, propiciando condições verdadeiras de publicidade, e que fortaleçam a capacidade tanto do Estado quanto dos próprios cidadãos de impor sanções sobre os infratores nos casos em que o interesse público é violado.

A Figura 01, nesse sentido, esboça essa perspectiva que, partindo da Lei de Acesso à informação, integra a transparência, a publicidade e o enforcement como três condições necessárias para o fortalecimento do controle da corrupção no Brasil em suas três dimensões.

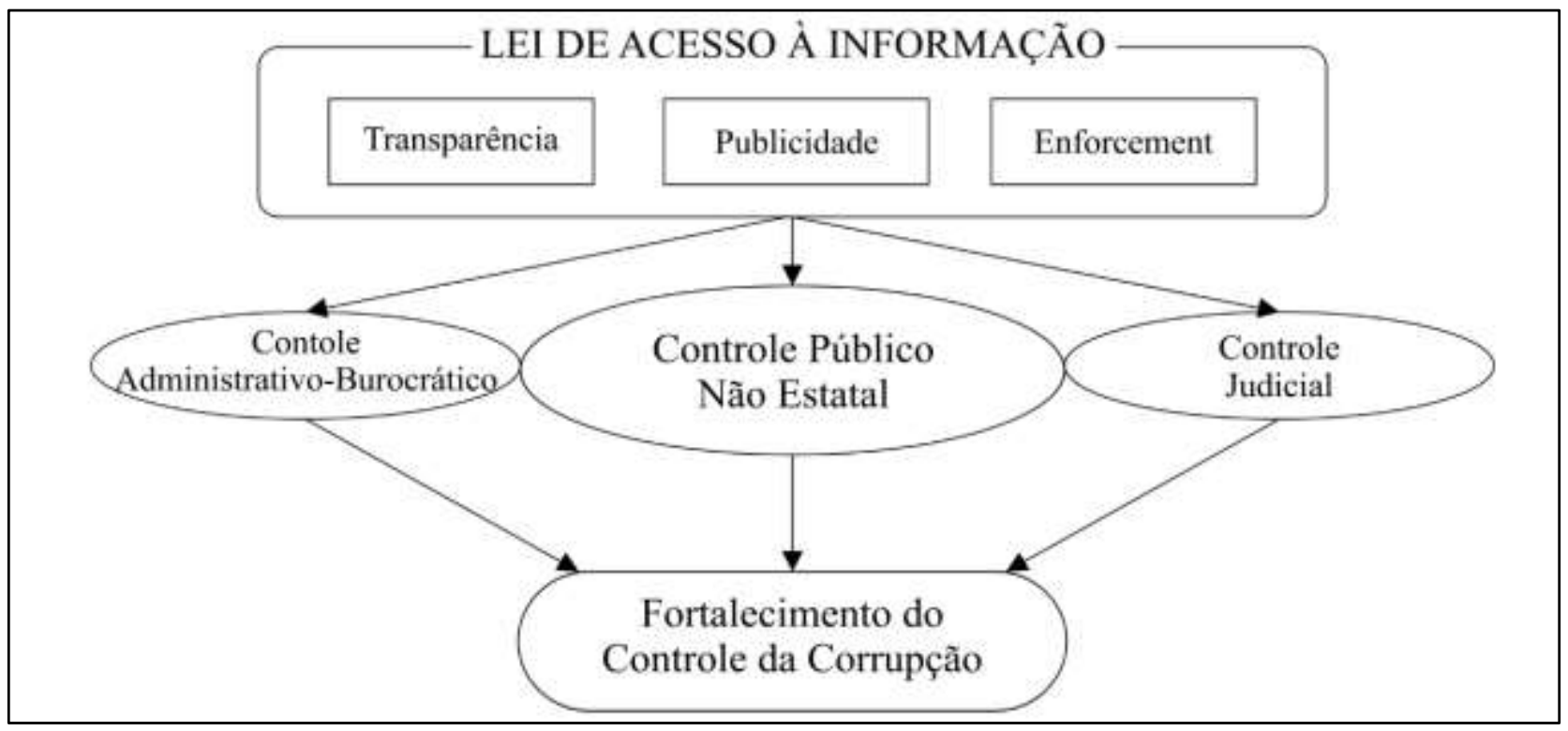

Figura 1: Relação entre a Lei de Acesso à Informação e o controle da corrupção

Fonte: Elaboração própria. 
Cumpre destacar, que essa abordagem não tem como objetivo propor uma resposta para os problemas relacionados ao controle da corrupção e ao acesso à informação no Brasil. Busca-se mostrar que a Lei no. 12.527/11, por si só, é condição necessária, porém, insuficiente para se garantir um acesso à informação mais amplo e um maior controle e participação por parte da sociedade civil nas questões atreladas ao Estado. Além de transparência, é necessário que as políticas e normas elaboradas pelo governo tenham o poder de se fazerem cumprir (enforcement), e que ocorram em condições de publicidade (Filgueiras, 2011a), de modo que os cidadãos possam ouvir, serem ouvidos e ouvirem os outros. A aprovação da Lei de Acesso à Informação, mesmo sendo tardia em comparação com outros países, pode ser considerada um grande avanço do Brasil. Porém, a simples entrada em vigor de uma lei representa somente a garantia de se poder valer do direito nela previsto.

Destaca-se, aliás, que ainda existe um distanciamento entre a implantação e a verdadeira implementação da Lei de Acesso à Informação, considerando os frutos que ela pode gerar para a sociedade e para o próprio Estado. O caminho que deve ser traçado entre esses dois aspectos envolve mudanças organizacionais, operacionais e, principalmente, socioculturais. A disponibilização dos dados públicos nos portais eletrônicos dos entes que gerenciam recursos públicos de nada adiantará se não houver por parte dos cidadãos o menor interesse em consultálos ou de pedir informações que não estão acessíveis. Também não adiantará aprimorar os mecanismos de controle administrativo-burocrático e judicial se não houver uma integração deles com o controle exercido pela sociedade. Na busca por uma política verdadeiramente transparente, que possibilite uma interação dinâmica entre as três dimensões do controle da corrupção, o Estado e a sociedade devem caminhar juntos.

Não pretende-se com esta proposta desmerecer ou mesmo menosprezar os avanços e as vantagens que a Lei de Acesso à Informação trouxe para a administração pública, entretanto, acredita-se que as perspectivas sobre ela devem ser ampliadas no sentido de abrir as portas para outras políticas que possam, de algum modo, romper ou ao menos diminuir a passividade que está profundamente encrustada na sociedade brasileira, seja mediante o estabelecimento de condições de publicidade, seja por meio da imposição de sanções. A maior contribuição deste estudo, portanto, é apresentar reflexões que ampliem a compreensão da transparência, na qual se inclui a Lei de Acesso à Informação, para além do estabelecimento de regras e de mecanismos burocráticos de controle, por meio de uma perspectiva que também integre a publicidade não apenas como uma possibilidade de acessar dados públicos e sim como uma prática que exige a participação ativa da sociedade civil e que, acaso descumprida pela administração pública, seja passível de sanção tanto pelos cidadãos quanto pelo Estado.

Deste modo, compreende-se que não cabe ao Estado apenas fornecer informações que possam ajudar os cidadãos a fiscalizarem os gastos públicos, é necessário, também, oferecer oportunidades para que esse controle exercido pela sociedade possa realmente contribuir para a 
interação entre a administração pública e o administrado. Muito mais que permitir um maior acesso às informações públicas, o próprio cidadão precisa ter consciência do seu papel ativo na sociedade. Mudar a passividade dos brasileiros frente ao poder público é algo que nenhuma lei ou mecanismo de controle resolverá, a não ser que, antes disso, o próprio cidadão tenha alterado a sua forma de se relacionar com o Estado.

\section{CONSIDERAÇÕES FINAIS}

A partir das discussões feitas neste ensaio observa-se que o Estado brasileiro ainda possui um papel centralizador na estruturação da vida social e na garantia dos direitos dos cidadãos. O seu principal foco tem sido o aprimoramento de mecanismos burocráticos de controle e a edição de normas mais severas. Não se pode negar que tais instrumentos realmente são necessários e dão sustentação ao controle da corrupção no Brasil, porém, são insuficientes. Ainda falta uma maior integração com a sociedade, que também tem a função de fiscalizar a gestão pública e de participar de suas decisões. A Lei no. 12.527/11, além de garantir o direito de acesso às informações que são coletadas, produzidas e armazenadas pelas entidades públicas, representa um passo de tantos outros que ainda devem ser dados a fim de se consolidar uma política que garanta não só o acesso à informação, mas que funcione como um verdadeiro incentivo à maior participação.

Nesse contexto, mais que os obstáculos operacionais, acredita-se que o maior entrave à efetividade da LAl está relacionado à mudança da cultura passiva dos cidadãos brasileiros de se conformar com aquilo que o Estado Ihe oferece. É comum os brasileiros reivindicarem dos seus representantes uma postura mais rígida frente às práticas corruptas, bem como a edição de leis mais severas. Pouco se vê, entretanto, exigências relacionadas à uma maior aproximação entre a administração pública e a sociedade. Enquanto os cidadãos enxergarem as informações disponibilizadas pelos entes públicos como dados que na prática não tem nenhuma aplicação ou que são úteis apenas para o atendimento de interesse pessoais, acredita-se que não é possível falar que foi efetivamente implementada uma política de acesso à informação pública, visto que um dos seus objetivos, talvez o primordial, seja promover o controle social.

Como contribuição para o campo da administração pública, o presente estudo avança nas discussões de que as reformas com foco no aumento da transparência devem ser acompanhadas de medidas para estimular o acesso e utilização das informações disponíveis e fortalecer a capacidade dos gestores de agir com idoneidade. Essa abordagem permite compreender que os mecanismos burocráticos e judiciais de controle da corrupção, assim como a consolidação de uma lei que garante ao cidadão o acesso às informações públicas, não são o bastante para a consolidação de uma política na qual os cidadãos possam ter voz. Seu objetivo é evidenciar que além dos incentivos criados pelo Estado, o cidadão também deve adotar uma postura mais ativa frente aos seus representantes, que não se resuma à apenas o seu voto. 
Nesse sentido, contribui para o debate a respeito da necessidade de uma maior integração entre o controle administrativo-burocrático, o judicial e o público não estatal, demonstrando que o ponto chave para um controle da corrupção mais eficaz está na junção dessas três dimensões. Outra questão que este trabalho tangencia é a discussão sobre o uso das tecnologias de informação e comunicação e de sua acessibilidade pelos cidadãos.

Cabe questionar, assim, de que maneira a disponibilização de dados pelos entes públicos influenciam nas decisões dos cidadãos e se somente a divulgação espontânea e a possibilidade de requerer informações são o bastante para se falar em transparência e maior participação da sociedade nos assuntos do Estado. Questiona-se, enfim, se o livre acesso às informações públicas, de fato, tem despertado um maior interesse nos cidadãos em tomar a frente ou de pelo menos participar de forma ativa nos processos de escolhas e decisões públicas. Dessa forma, para pesquisas futuras recomenda-se investigar se as previsões da LAI realmente correspondem aos anseios dos cidadãos, se efetivamente promovem a accountability e quais as possíveis razões para o descumprimento da legislação pelos entes públicos. Essas são questões que carecem de um debate mais aprofundado e que o Estado, por si só, não conseguirá resolver se não houver engajamento dos cidadãos no alcance do interesse público.

\section{REFERÊNCIAS}

Abrucio, F. L., \& Loureiro, M. R. (2004). Finanças públicas, democracia e accountability. In: Arvate, P. R.; Biderman, C. Economia do Setor Público no Brasil. Rio de Janeiro: Elsevier/Campus

Abrucio, F. L., Pedroti, P., \& Pó, M. V. (2010). A formação da burocracia brasileira: a trajetória e o significado das reformas administrativas. In: Loureiro, M. R.; Abrucio, F. L.; Pacheco, R. S. (Orgs.). Burocracia e Política no Brasil: desafios para a ordem democrática no século XXI. Rio de Janeiro: Ed. fgv, pp. 27-71.

Albuquerque, C., Medeiros, M., \& Feijó, P. H. (2006). Gestão de finanças públicas. Brasília: Gestão Pública.

Andrade, D. M., Castro, C. L. C., \& Pereira, J. R. (2012). Cidadania ou "estadania" na gestão pública brasileira? Revista de Administração Pública, v. 46, n. 1, p. 177-190.

Anechiarico, F., \& Jacobs, J. (1996). The persuit of absolute integrity. How corruption control makes government ineffective. Chicago: The University of Chicago Press.

Angélico, F. (2012). Lei de acesso à informação pública e seus possíveis desdobramentos para accountability democrática no Brasil. Dissertação (mestrado) - Escola de Administração de Empresas de São Paulo, Fundação Getúlio Vargas, São Paulo.

Angélico, F., \&Teixeira, M. A. C. (2012). Acesso à informação e ação comunicativa: novo trunfo para a gestão social. Desenvolvimento em Questão, 10(21), 7-27. 
Aranha, A. L. M. (2015). A Rede Brasileira de Instituições de Accountability: Um Mapa Do Enfrentamento Da Corrupção Na Esfera Local." Tese (Doutorado). Universidade Federal de Minas Gerais - UFMG.

Araujo, J., \& Tejedo-Romero, F. (2016). Local government transparency index: determinants of municipalities' rankings. International Journal of Public Sector Management, v. 29, n. 4, p. 327-347, 29 abr.

Avritzer, L., \& Filgueiras, F. (2011). Corrupção e controles democráticos no Brasil. Brasília, DF: CEPAL. Escritório no Brasil/IPEA. (Textos para Discussão CEPAL-IPEA, 32). 40p.

Barboza Filho, R. (2008). Judiciário. In: Avritzer, L., Bignoto, N., Guimaraes, J., Starling, H. M. M. (Org.). Corrupção: ensaios e críticas. Belo Horizonte: Editora UFMG, p. 535-541.

Barreda, M. (2014). The quality of democratic accountability: a comparative view of Latin America. Canadian Journal of Political Science, Waterloo, v. 47, n. 2, p. 307-326.

Bastida, F., \& Benito, B. (2007). Central government budget practices and transparency: An international comparison. Public Administration, v. 85, n. 3, p. 667-716.

Bernardes, M. B., Santos, P. M., \& Rover, A. J. (2015). Ranking das prefeituras da região Sul do Brasil: uma avaliação a partir de critérios estabelecidos na Lei de Acesso à Informação. Revista de Administração Pública, v. 49, n. 3, p. 761-792.

Brasil. (1988). Constituição da República Federativa do Brasil. Brasília: Senado.

Brasil. (2000). Lei Complementar no. 101, de 4 de maio de 2000. Estabelece normas de finanças públicas voltadas para a responsabilidade na gestão fiscal e dá outras providências. Diário Oficial [da] República Federativa do Brasil, Brasília, DF, 05/05/2000. Recuperado em 30 maio, 2017 de http://www.planalto.gov.br/ccivil_03/leis/LCP /Lcp101.htm.

Brasil. (2009). Lei Complementar no. 131, de 27 de maio de 2009. Acrescenta dispositivos à Lei Complementar no. 101, de 4 de maio de 2000. Diário Oficial [da] República Federativa do Brasil, Brasília, DF, 28/05/2005. Recuperado em 30 maio, 2017 de: http://www.planalto.gov.br/ccivil_03/leis/lcp /lcp131.htm.

Brasil. (2011). Lei no. 12.527, de 18 de novembro de 2011. Regula o acesso a informações previsto no inciso XXXIII do art. 5o, no inciso II do § 30 do art. 37 e no § 20 do art. 216 da Constituição Federal; altera a Lei no 8.112, de 11 de dezembro de 1990; revoga a Lei no 11.111, de 5 de maio de 2005, e dispositivos da Lei no 8.159, de 8 de janeiro de 1991; e dá outras providências. Diário Oficial [da] República Federativa do Brasil, Brasília, DF, 07.06.2010. Recuperado em 30 maio, 2017 de http://www.planalto.gov.br/ccivil_03/_ato20112014/2011/lei/l12527.htm.

Bueno, R. L. P., Brelàz, G., \& Salinas, N. S. C. (2016). Administração Pública Brasileira no Século 21: Seis Grandes Desafios. Revista do Serviço Público, v. 67, n. Ed. Especial, p. 7-28.

Campos, E. B. (2004). Controle social das políticas públicas: notas para debate. Belo Horizonte. 
Carvalho, J.M. (2007). Cidadania no Brasil: o longo caminho. 9. ed. Rio de Janeiro: Civilização Brasileira.

Controladoria-Geral da União. (2013). Guia técnico de regulamentação da Lei de Acesso à Informação em Municícios e check list. 2013. Brasília, maio. Recuperado em 30 maio, 2017 de http://www.cgu.gov.br/Publicacoes/transparencia-publica/brasil-transparente/arquivos/ guia_checklist.pdf.

Cruz, C. F., Ferreira, A. C. S., Silva, L. M., \& Macedo, M. A. S. (2012). Transparência da gestão pública municipal: um estudo a partir dos portais eletrônicos dos maiores municípios brasileiros. Revista de Administração Pública, 46(1), 153-176.

Curtin, D., \& Meijer, A. J. (2006). Does transparency strengthen legitimacy? Information Polity, v. 11 , p. 109-122.

Dagnino, E. (2004). Sociedade civil, participação e cidadania: De que estamos falando? In: Mato, D. (Org). Políticas de ciudadanía y sociedad civil en tiempos de globalización. Caracas: Faces; Universidad de Venezuela, p. 95-111.

Etzioni, A. (2010). Is transparency the best disinfectant? The Journal of Political Philosophy, v. 18, n. 3, p. 389-404.

Figueiredo, V. da S., \& Santos, W. J. L. (2014). Transparência e participação social da gestão pública: análise crítica das propostas apresentadas na 1aㅡ Conferência Nacional sobre Transparência Pública. Revista de Contabilidade e Controladoria, UFPR, Curitiba, PR, v. 6, n. 1, p. 73-88.

Figueiredo, V., \& Gazoni, R. (2016). Transparência nos sites dos municípios do estado do rio de janeiro. Revista Contabilidade e Controladoria, v. 8, n. 2, 18 ago.

Filgueiras, F. (2008). Corrupção, democracia e legitimidade. Belo Horizonte: Editora UFMG.

Filgueiras, F. (2011a). Além da transparência: accountability e política da publicidade. Lua Nova [online]. №.84, pp. 65-94.

Filgueiras, F. (2011b). Sociedade civil e accountability societal no controle da corrupção no Brasil. In XXXV Encontro Anual da ANPOCS. Anais. Belo Horizonte-MG.

Filgueiras, F., \& Aranha, A. L. M. (2011). Controle da Corrupção e Burocracia da Linha de Frente: Regras, Discricionariedade e Reformas no Brasil. DADOS - Revista de Ciências Sociais, Rio de Janeiro, vol. 54, no 2, p. 349 a 387.

Filho, A. (2005). O desafio de implementar uma gestão pública transparente. In: X Congresso CLAD, 18-21 oct, 2005, Santiago, Chile. Anais. Santiago: CLAD.

Gingerich, D. (2006). Corruption in general equilibrium: political institutions and bureaucratic performance in South America. Tese de Doutorado. Cambridge, Mass. 
Graaf, G. (2007). Causes of corruption: towards a contextual theory of corruption. Public Administration Quarterly, v. 31, n. 1, p. 39-86.

Instituto Brasileiro de Geografia e Estatística. (2016). Estimativas populacionais para os municípios e para as Unidades da Federação brasileiros em 01.07.2016. Recuperado em 30 maio, 2017 de http://www.ibge.gov.br/home/estatistica/populacao/estimativa2016/ estimativa_dou.shtm.

Iquiapaza, R. A., \& Amaral, H. F. (2007). Reflexões do Impacto da Corrupção no Desenvolvimento Econômico: Uma Revisão na Economia Brasileira. Munich Personal Repec Archive. 2007.

Jardim, J. M. (1999). Transparência e opacidade do Estado no Brasil: usos e desusos da informação governamental. Niterói: EdUFF.

Klitgaard, R. Controlling Corruption. Berkeley: University of California Press, 1998.

Koppell, J. G. S. (2005). Pathologies of accountability: ICANN and the Challenge of "Multiple Accountabilities Disorder". Public Administration Review. Yale, v.65, n.1, p. 94-108.

Licht, J. F. (2014). Policy area as a potential moderator of transparency effects: an experiment. Public Administration Review, v. 74, p. 361-371.

Loureiro, M. R, T. M. A.; \& Moraes, T. C. (2009). Democratização e Reforma do Estado: o desenvolvimento institucional dos tribunais de contas no Brasil recente. Revista de Administração Pública (Impresso), v. 43, p. 739-774.

Macadar, M. A., Freitas, J. L., \& Moreira, C. R. (2015). Transparência como elemento fundamental em governo eletrônico: uma abordagem institucional. Revista Gestão \& Tecnologia, v. 15, n. 3, 2015.

Martins, J. A. (2008). Corrupção. São Paulo. Globo.

Medeiros, A. K., Crantschaninov, T. I., \& Silva, F. C. (2013). Estudos sobre accountability no Brasil: meta-análise de periódicos brasileiros das áreas de administração, administração pública, ciência política e ciências sociais. Revista de Administração Pública, 47(3), 745-775.

Mendanha, G. M. (2009). O direito de acesso à informação como fundamento da transparência. Revista da CGU, Brasília, v. IV, n. 6, p. 59-70, set.

Mendel, T. (2009). Liberdade de informação: um estudo de direito comparado. Brasília: UNESCO.

Michener, G., \& Bersch, K. (2011). Conceptualizing the quality of transparency. Political Concepts, v. $49,1-27$.

Michener, G. (2011). Conceptualizing the quality of transparency. In: 1st Global Conference nn Transparency. Annals. Newark.

Michener, G. (2016). Transparência Local no Brasil: Avaliando a aplicação da Lei de Acesso nos estados e nas grandes cidades. Rio de Janeiro: FGV e Open Society Foundations. 
Michener, G., \& Bersch, K. (2013). Identifying transparency. Information Polity, v. 18, p. 233-242.

Michener, G., Moncau, L. F. M., \& Velasco, R. (2014). Estado brasileiro e transparência: avaliando a aplicação da Lei de Acesso à Informação. Rio de Janeiro: FGV e Open Society Foundations.

O’Donnell, G. (1998). Accountability horizontal e novas poliaquias. In: Lua Nova, № 44, pp.27-54.

O’Donnell, G. (1991). Democracia delegativa. Novos estudos, v. 31, p. 25-40.

Oliveira Júnior, T. M., Jordão, C. S., \& Castro Junior, J. L. P. (2016). Planejamento governamental e acesso à informação no Brasil: lacunas, complementariedade e mudança institucional. Revista Administração em Diálogo, v. 18, n. 1, p. 112-132.

Olivieri, C. (2011). Os controles políticos sobre a burocracia. Rev. Adm. Pública [online], vol.45, n.5, pp.1395-1424.

Peisakhin, L., \& Pinto, P. (2010). 'Is transparency an effective anti-corruption strategy? Evidence from a field experiment in India'. Regulation \& Governance, 4 (3), 261-280.

Peruzzotti, E. (2008). Accountability. In: Avritzer, L., Bignoto, N., Guimaraes, J., Starling, H. M. M. (Org.). Corrupção: ensaios e críticas. Belo Horizonte: Editora UFMG, p. 477-484.

Peruzzotti, E., \& Smulovitz, C. (2006). Social accountability. In: Enforcing the rule of law: social accountability in the new Latin American Democracies. Pittsburgh: University of Pittsburgh Press, p. 9-10.

Pinho, J., A. G., \& Sacramento, A. R. (2009). Accountability: já podemos traduzi-la para o português? Revista de Administração Pública, v. 43, n. 6, p. 1343-1368, 2009.

Power, T. J, \& González, J. (2003). Cultura Política, Capital Social e Percepções sobre Corrupção: uma investigação quantitativa em nível mundial. Revista de Sociologia e Política. N. 21. Curitiba.

Przeworski, A. (1998). Sobre o desenho do Estado: uma perspectiva agent x principal. In Bresser Pereira, L. C.\& Spink, P. (orgs). Reforma do Estado e Administração Pública gerencial. Rio de Janeiro: FGV, p.39-73

Raupp, F. M. (2014). Prestação de contas de executivos municipais de Santa Catarina: uma investigação nos portais eletrônicos. Administração Pública e Gestão Social, v. 6, n. 3, p. 151158.

Raupp, F. M., \& Pinho, J.A. G. (2013). Accountability em câmaras municipais: uma investigação em portais eletrônicos. Revista de Administração, v. 48, n. 4, p. 770-782.

Schedler, A. (1999). Conceptualizing Accountability. In: Schedler, A., Diamond, L., Plattner, M. F. (Eds.). The Self-Restraining State: Power and Accountability in New Democracies. Colorado: Lynne Rienne, p. 13-28. 
Souza, F. J. B., Silva, S. A. M., \& Gomes, A. O. (2017). Corrupção no Setor Público: Considerações a Partir da Literatura Internacional. In: EnAnpad, São Paulo. Anais.

Suzart, J. A. da S. (2012). Ser ou não ser independente? Um estudo exploratório sobre a independência das instituições superiores de auditoria e o nível de transparência fiscal dos países. Revista Universo Contábil. v. 8, n. 3, p. 24-39.

Vigoda-Gadot, E., \& Meiri, S. (2008). New public management values and person organization fit: a socio-psychological approach and empirical examination among public sector personnel.

Public Administration, London, v.86, n.1, p.111-131.

Zuccolotto, R., \& Teixeira, M. A. C. (2015). Gestão Social, Democracia, Representação e

Transparência: evidências nos estados brasileiros. Revista de Ciências da Administração. V.17 Edição Especial de Dezembro.

\section{COMO CITAR ESTE ARTIGO:}

Macedo, S.V., Valadares, J.L. (2020). "De Samba-Enredo de Carnaval ao Congresso Nacional”: reflexões sobre a Lei de Acesso à Informação frente ao controle da corrupção no Brasil. Holos, 36(4), 1-24.

\section{SOBRE OS AUTORES}

\section{SUÉLEM VIANA MACEDO}

Doutoranda do Programa de Pós-Graduação em Administração (PPGADM) na Universidade Federal de Viçosa (UFV); Mestre em Administração pela Universidade Federal de Viçosa (UFV). E-mail: susu.viana@hotmail.com

ORCID ID: https://orcid.org/0000-0002-1610-1856

\section{JOSIEL LOPES VALADARES}

Professor do Programa de Pós-Graduação em Administração (PPGADM) na Universidade Federal de Viçosa (UFV); Doutor em Administração pela Universidade de Lavras. E-mail: adm josiel@yahoo.com.br ORCID ID: https://orcid.org/0000-0002-2559-9617

Editor(a) Responsável: Francinaide de Lima Silva Nascimento Pareceristas Ad Hoc: Allan Gustavo Freire da Silva e José da Paz

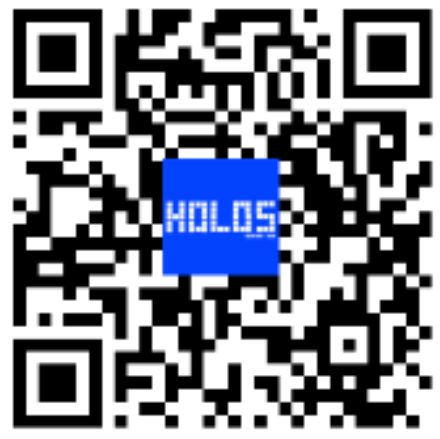

Recebido: 26 de março de 2020 
Aceito: $\mathbf{2 4}$ de junho de $\mathbf{2 0 2 0}$

Publicado: 01 de julho de 2020 